\title{
Perkloretilen’in in vitro Sitotoksik Etkisinin Brine Shrimp Letalite Testi ile Araştırılması
}

\author{
Ümit ÜNSAL1 ${ }^{1 D}$, Tülay AŞKIN ÇELİK ${ }^{2}$ (D) \\ 1İMİ Koleji, İsmet Paşa Mahallesi Sodra Doğakent Evleri Sk. No:92 Milas/MUĞLA, ${ }^{2}$ Adnan Menderes Üniversitesi Fen- \\ Edebiyat Fakültesi, Biyoloji Bölümü, AYDIN \\ $\bowtie: \underline{\text { tcelik@adu.edu.tr }}$
}

\section{ÖZET}

Perkloroetilen (PERC), kuru temizleme endüstrisinde çözücü, yağ giderici ve temizleyici olarak yaygın bir şekilde kullanılmaktadır. Perkloroetilen, güçlü ve etkili bir temizleyici olup giysilerin buruşmasını ve renginin solmasını engeller. Kuru temizleme dükkanlarının en az üçte ikisi kuru temizleme işlemlerinde perkloroetilen’i kullanmaktadır. Uluslararası Kanser Araştırmaları Ajansı (IARC, 1995) Perkloroetileni insan karsinojeni olarak Grup2A içerisine almıştır ve kurutemizleme endüstrisinde çalışan insanlar için kanserojen olabileceğini belirtmiştir. PERC'in kuru temizlemede çalışan işçilerde cilt lezyonlarının yanı sıra, lenfosarkom, lösemi, kolon, akciğer ve ürogenital kanserlere neden olduğuna dair çalışmalar bulunmaktadır. Bu çalışmada saf Perkloroetilen'in Artemia salina larvaları üzerindeki potansiyel sitotoksik etkisi Brine Shrimp Letalite Testi ile araştırılmıştır. Denemelerde negatif kontrol olarak tuzlu su, çözücü kontrol olarak etanol ve pozitif kontrol olarak da Mitomisin-C (MMC) kullanılmıştır. Çalışmanın sonuçları, LC50 değerlerine göre, in vitro ortamda PERC'e 24 saat maruz birakılan A.salina larvaları üzerindeki sitotoksik etkinin sadece 1000 ppm'lik PERC uygulanması sonucunda ortaya çıktığını, diğer konsantrasyon aralıklarında (10 ve 100 ppm) ise sitotoksik aktivitesinin olmadığını göstermiştir.

\section{DOI:10.18016/ ksudobil.407505}

Makale Tarihçesi

Geliş Tarihi : 19.03.2018

Kabul Tarihi : 16.04.2018

Anahtar Kelimeler
Artemia salina,
Brine Shrimp
Letalite Testi,
Perkloroetilen,
Sitotoksik etki

Araştırma Makalesi

\section{Investigation of in vitro Cytotoxic Effects of Perchloroetylene by Using Brine Shrimp Lethality Assay}

\begin{abstract}
Perchlorethylene $(\mathrm{PERC}=$ tetrachlorethylene $)$ is widely used in industry as a dry-cleaning solvent, degreaser, and cleaner. PCE is a useful solvent in the dry-cleaning industry because it is an effective cleaner and prevent shrinking and color fading of garments. At least two-thirds of dry cleaners use PCE as a solvent in their dry-cleaning operations. The International Agency for Research on Cancer (IARC) included PCE to the Group 2A probable human carcinogen, and considers it as possibly carcinogenic to the dry-cleaning industry workers. It has been showed that PERC causes human skin lesions as well as lymphosarcoma, leukemia, colon, lung and urogenital cancers in dry cleaning workers. In this study, the potential cytotoxic effect of pure Perchloroethylene on Artemia salina larvas was investigated by Brine Shrimp Letality Assay. In experiments saline was used as negative control, ethanol was used as solvent control and Mytomicin$\mathrm{C}(\mathrm{MMC})$ was used as positive control. The results of this study $\left(\mathrm{LC}_{50}\right.$ values) showed that the cytotoxic effect on the $A$. salina larvae exposed to PERC for 24 hours in vitro was only due to the application of 1000 ppm of PERC, while the other concentrations (10 and $100 \mathrm{ppm}$ ) did not have cytotoxic activity.
\end{abstract}

\section{Article History}

Received : 19.03.2018

Accepted : 16.04.2018

\section{Keywords}

Artemia salina,

Brine Shrimp

Lethality Assay,

Perchloroethylene,

Cytotoxic effect,

\section{Research Article}

To cite : Ünsal Ü, Aşkın Çelik T 2018. Perkloretilen'in in vitro Sitotoksik Etkisinin Brine Shrimp Letalite Testi ile Araştırılması. KSÜ Tarim ve Doğa Derg 21(5),644-649, 2018. DOI:10.18016/ksudobil.407505 


\section{GİṘŞ}

Günümüzde Avrupa'da çok yaygın olan kuru temizleme endüstrisi, Türkiye'de de hızla yaygınlaşmaktadır. Tekstil ürünlerini temizlerken ürünlerde hasarın oluşmasının önlenmesi, görünümlerinin ilk günkü yeniliğinde muhafaza edilmesi ve renklerinin değişmemesi amaçlanır. Tekstil ürünlerinin üzerinde bulunan kir ve lekeleri çıkarma işlemleri genellikle sulu yıkama ile yapılmaktadır. Ancak bazı tekstil ürünleri su ya da alkali olan deterjanlara karşı hassastır ve bu da ürünün bozulmasına yol açmaktadır. Bunun yanı sıra yağ ve petrol bazlı lekeler de sulu yıkama ile çıkarılamamaktadır. Bu nedenle su ile yıkamaya alternatif olarak geliştirilen kuru temizleme ile tekstil ürünlerinin kirlerden arındırılması, lekelerin çıkarılması hedeflenmektedir. Kuru temizlemenin temel amacı organik solventler kullanarak çamaşırları kirlerden temizlemektir. Solventler, yağ esaslı kirleri çözmek suretiyle temizlerken mekanik, mekanik hareketlerle de toz gibi diğer kirleri uzaklaştıran organik çözücüdürler. Leke çıkarmak için kullanılan kuru temizleme solventleri PERC, hidrokarbonlar, silika bazlı çözücüler ve diğer ticari maddelerdir. Kuru temizlemede kullanılan organik çözücüler genelde renksiz ve şeffaf olup, kendilerine has bir kokusu vardır (Blair ve ark., 1990).

Kuru temizleme endüstrisi 19. yüzyılda ilk olarak Avrupa'da faaliyete başlamıştır. Başlangıçta en çok kullanılan kuru temizleme solventleri petrol bazlı olup benzen, kerosen, nafta ve benzin içermekteydi. Petrol bazlı solventler, çok uçucu özelliğe sahip olduklarmdan dolayl kuru temizlemede kullanıldıklarında patlama ve yangın oluşturma riskleri oldukça yüksektir. Daha sonraları kullanılan trikloretilen ve karbon tetraklorid gibi çözücülerin de zararlı etkilerinin olduğu ortaya çıkmıştır. Bu sıvıların yerini sırasiyla kerosen benzeri etilen ve 1950'li yıllardan itibaren de renksiz, alev almayan ve patlayıcı olmayan sentetik bir sıvı olan perkloretilen (PERC, $\mathrm{C}_{2} \mathrm{Cl}_{4}$ ) ve 1990 'l ylllardan sonra da (Blair ve ark., 1990) propilen glikoleter, sıvı karbondioksit, $\mathrm{n}^{-}$ propil bromür, silikon bazlı solvent, dibutoksimetan ve hidrokarbon esash yeni solventler almışlardır (Oran, 2016).

Kuru temizlemede kullanılan PERC (= tetrakloroetilen), hidrofilik olmasindan dolayı, tekstil liflerini bozmayan bir özelliğe sahiptir. Kumaş liflerinin temizleme sirasında bünyelerine aldı ğ PERC kumaşı bozmadan, kumaş üzerinde ve bünyesinde su gibi nemlilik bırakmadan, kumaşı şişirip, kısaltmadan ve çektirmeden kumaşı kendi normal boyutunda birakarak $70 \quad{ }^{\circ} \mathrm{C}$ 'de kolayca buharlaşmaktadır. PERC, buharlaştığında keskin ve tatlı sert bir koku çıkartmaktadır (Anonim, 2004).

PERC buharlaşma yoluyla atmosfere girer. Yapılan çalışmalar Avrupa'da kuru temizleme endüstrisinde çalışan yaklaşı 1,5 milyonun üzerindeki kuru temizleme işçisinin her yıl ortalama olarak $59 \mathrm{ppm}$ ve uygulamaya bağlı olarak daha yüksek düzeyde PERC'e maruz kaldığını göstermektedir (Ünsal, 2013). Türkiye'de kuru temizlemede endüstrisinde çalışan iş̧̧i sayısı ve maruz kalınan PERC miktarı kesin olarak bilinmediği için, ülkemizdeki işçilerin durumu hakkında kesin bir şey söylemek mümkün değildir. PERC'e uzun süre temas etme sonucunda deride yaygın tahriş, solunum sisteminde düzelmeyen alerjik rahatsızlıklar ile böbrek ve karaciğerde hasarların görüldüğü, PERC'e maruz kalan hamilelerde nedensiz düşüklerin daha sık gözlendiği, hem kadınlarda hem de erkeklerde doğurganlık oranının azaldığ bildirmektedir (Fişek ve Piyal, 1989; Karakaya, 1996).

PERC'in potansiyel genotoksik etkisi bakteri, maya ve memeli hücreleri gibi farklı in vitro test sistemlerinde araştırılmıştır (ECETOC, 1990., IARC, 1995., ATSDR., 1997). PERC'in, in vitro muameleyi takiben farkl hücrelerde mikronukleus oluşumuna ve kardeş kromatid değişimine (SCEs) (Ünsal, 2013) ve tümör dokularında genotoksik etkilere neden olduğuna dair çalışma örnekleri bulunmaktadır (Spencer ve ark., 2002). Walles (1986), farelere intraperitonal (i.p) yolla 4-8 mmol/kg (663-1326 mg/kg) PERC uygulandıktan 1 saat sonra, farelerin karaciğer ve böbrek dokularında artan oranlarda tek iplikli DNA zincir kırıklarının ortaya çıktığını ancak akciğer dokularında bu tür bir hasara rastlanmadığını bildirmiştir. Potter ve ark., (1996), erkek F344 sıçanlarına gavaj yolu ile 1.000 $\mathrm{mg} / \mathrm{kg}$ PERC verildikten sonra sıçanların böbrek hücrelerinde, DNA zinciri kırılmalarında herhangi bir artış olmadığını belirlemişlerdir. $5 \mathrm{mM}(\sim 830 \mathrm{mg} / \mathrm{L})$ tetrakloretilen'in insan kan hücrelerinde kardeş kromatid değişimlerine (SCE) neden olduğu (Muzzullo ve ark., 1987) ve hücre canlılığını \% 40 oranında azalttığ (Hartmann ve Speit, 1995), kültüre edilen Cin hamster ovaryum hücrelerinde (Wang ve ark., 2001) ve insan periferal kan hücrelerinde mikronukleuslara da neden olduğu (White ve ark., 2001) bildirilmiştir.

Artemia salina Crustacea alt şubesi, Branchiopoda sınıf, Anostraca takımına bağlı primitif kabuklular arasında yer alan, doğada tropik ve ılıman bölgelerde doğal ve yapay tuz göllerinde yaşayan bir kabuklu türüdür. Ergin bireyleri \% 1 ile \% 235 tuzluluk arasında ve $10-35{ }^{\circ} \mathrm{C}$ arasında yaşayabilirler. $A$. Salina, yaşam devri boyunca dayanıklı yumurtalar (kistler) oluşturması nedeniyle, su canlılarının özellikle de balıkların beslenmesinde 1920'den bu yana canlı yem olarak kullanılmaktadır (Anonim, 2008). A. salina larvaları, günümüzde biyolojik aktiviteleri araştırılan örneklerin toksik etkilerinin araştırılmasında oldukça geniş bir şekilde kullanılmaktadır. Artemia, ekotoksisite testleri için kullanılan önemli bir test organizmasıdır (Nunes ve ark., 2006). Toksik maddelerin $A$. salina larvalarına üzerindeki öldürücü etkisi, hızlı ve basit bir yöntem 
olan "Brine Shrimp Letalite Testi"in kullanılmasina olanak sağlamaktadır (Choudhary ve Thomsen, 2001, Libralato ve ark., 2016). Bu test, Michael ve arkadaşları tarafından 1959 yılında geliştirilmiş ve pek çok kimyasal maddenin veya bitki ekstrelerinin potansiyel toksik etkileri için kullanılan, elverişli bir yöntem olarak benimsenmiştir (Insanu ve ark, 2012, Rajabi ve ark., 2015). Toksisite testlerinde materyal olarak $A$. salina kullanmanin temel avantajları şunlardır: (1) hızlı bir yöntem olması (kist halinden larva oluncaya kadar geçen süre 28-72 saattir), (2) maliyetin ucuz olması, (3) ticari dayanıklı kistlerden (yumurta) çıkan larvaların homojen olması, (4) kültür gerekmeksizin yıl boyu kullanılabilir olması (Nunes ve ark., 2006; Manfra ve ark., 2012), (5) biyolojisi ve ekolojisi hakkında bilgi sahibi olunması, (6) laboratuvar koşullarında manipülasyonunun ve bakımının kolay olması, (7) küçük bir ortamda ve mikro plaklarda (well plate) bile rahatça üretilebilmeleri ve (8) çeşitli test koşullarına yüksek oranda uyum göstermesi (Nunes ve ark., 2006; Kokkali ve ark., 2011). Ayrıca, A.salina larvaları ile yapılan bu testin modifiye edilmiş şekli ile alınan sonuçlar, memeli hücre kültürleri ile yapılan toksisite testlerinde alınan sonuçlarla karşılaştırıldığında birbiriyle uyumlu sonuçların elde edilmektedir (Lewan ve ark., 1992).

$\mathrm{Bu}$ çalışmada kuru temizleme dükkânlarında kimyasal ve çözücü madde olarak yaygın bir şekilde kullanılan saf haldeki PERC'nin potansiyel sitotoksik etkisi; hızlı, kolay ve düşük maliyetli olması nedeniyle Brine Shrimp (Artemia salina) Letalite Testi yöntemi ile değerlendirilmiştir.

\section{MATERYAL ve METOT}

$\mathrm{Bu}$ çalışmanın materyalini oluşturan JBL marka $A$. salina kistleri, Aydın'da ticari faaliyet gösteren yerel bir akvaryumcudan ticari olarak satın alınmıştır.

Brine Shrimp Letalite Testi ile perkloretilen'in in vitro sitotoksik etkisinin belirlenmesi için Solis ve ark.,'nın (1993) yöntemi modifiye edilerek uygulanmıştır. $A$. salina yumurtaları, içerisinde tuzlu su bulunan (3,6 $\mathrm{g} / 100 \mathrm{~mL}) 500 \mathrm{ml}$ 'lik bir cam akvaryumda, bol oksijen verilerek ve suyun sıcaklığ $28{ }^{\circ} \mathrm{C}$, pH's 7-8 olacak şekilde inkübasyona bırakılmıştır. Kistlerden çıkacak larvaların kabın dış yüzeyine doğru yönelebilmesi için yapay bir ışık kaynağı kullanılmıştır. 48 saatlik inkübasyon sonucunda yumurtadan çıkıp olgunlaşan
Artemia larvaları pastör pipeti yardımı ile toplanarak, içerisinde 4,5 ml deniz suyu içeren 96'llk mikro plaklara, (her bir kuyucukta 10'ar adet larva olacak şekilde) konulmuştur. Denemelerde PERC'in üç farklı konsantrasyonu (10 ppm, $100 \mathrm{ppm}$ ve $1000 \mathrm{ppm})$ kullanılmıştır. 24 saat PERC ile muamele edildikten sonra, ölen ve yaşayan larvalar stereo mikroskop altında sayılıp, ölü ve yaşayan larva sayısı kaydedilmiştir. Ölüm yüzdesi aşağıdaki formül ile hesaplanmiştır:

\% Ölüm $=[$ (Test - Kontrol $) /$ Kontrol $] \times 100$

Denemelerde negatif kontrol olarak tuzlu su, çözücü kontrol olarak aynı miktar kadar ethanol (PERC ethanol ile çözdürüldüğü için $(1: 1$, v/v $)$ ve pozitif kontrol olarak da Mitomycin-C (10 ppm) kullanılmıştır.

\section{İstatistiksel Analiz}

Sonuçlar SPSS 16.0 istatistik paket programında Probit analizi ile değerlendirilmiş ve $\mathrm{LC}_{50}$ değerleri ile \% 95 güvenilirlik sınırları hesaplanmıştır.

\section{BULGULAR ve TARTIŞMA}

Bu çalışmada PERC'in in vitro sitotoksik aktivitesi, Brine Shrimp Letalite Testi ile araştırılmıştır. Brine Shrimp Letalite Testi ile denenen kimyasallarm $A$. salina larvalarının yarısının ölümüne yol açan konsantrasyonu ( $\mathrm{LC}_{50}$ ), aktif konsantrasyon olarak kabul edilmiştir (McLaughlin ve ark., 1998). Nguta ve ark., (2011)'a göre, $\mathrm{LC}_{50}$ değerleri 100 ppm'in altında

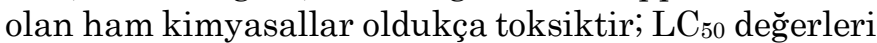
100 ppm-500 ppm arasinda olanlar orta derecede toksik, LC $\mathrm{L}_{50}$ değerleri 500 ppm-1000 ppm arasında olanlar zayıf toksik ve 1000 ppm'in üzerindeki $\mathrm{LC}_{50}$ değerlerine sahip kimyasallar ise, toksik olmayan kimyasallar olarak kabul edilir. Calışmada Probit analizi ile elde edilen veriler incelendiğinde, PERC'in 10 ppm-100 ppm arasında bulunan $\mathrm{LC}_{50}$ değerlerinin, alt ve üst güvenlik sınırları itibariyle toksisite sınırları içerisinde yer aldığını, bu konsantrasyon aralıkları içinde toksik olmadığını ortaya koymuştur. (Çizelge 1). Ancak PERC'in 1000 pmm'lik konsantrasyonu ile muamele edilen $A$. salina larvalarını \%50'sinden fazlasının öldüğ̈ü belirlenmiştir $\left(\mathrm{LC}_{50}<1000\right)$. Bu sonuç PERC'in yüksek konsantrasyonda A.salina larvaları üzerinde zayıf da olsa toksik etkisinin olduğunu göstermektedir (Tablo 1).

Tablo 1: PERC ile 24 saat muamele edilen $A$.salina larvalarında belirlenen LC $_{50}$ değerleri

\begin{tabular}{|l|l|l|l|}
\hline Muamele grupları & Süre (h) & Konsantrasyon (ppm) & LC $_{50}(\mathrm{ppm})$ \\
\hline Kontrol (tuzlu su) & 24 & 0 & $>1000$ \\
\hline Etanol (çözücü kontrol) & 24 & 100 & $>1000$ \\
\hline MMC & 24 & 10 & $<1000$ \\
\hline \multirow{3}{*}{ PERC } & \multirow{2}{*}{24} & 10 & $>1000$ \\
\cline { 2 - 4 } & & 100 & $>1000$ \\
\cline { 2 - 4 } & & 1000 & $<1000$ \\
\hline
\end{tabular}

PERC: Perkloroetilen; MMC: Mitomisin-C $\quad$ p $>0.05$ 
Kerster ve Schaeffer (1983) farklı kimyasal maddelerin teratojenik etkilerini Brine Shrimp Letalite Testi ile araştırdıklarında; kadmiyum, cıva, kurşun, çinko, bromoform, n-butilftalat, 1,2dikloroetan, nitrobenzen, tetrakloroetilen (perkloroetilen), toluen, 1,2,4-triklorobenzen ve 1,1,3trikloroetan'ın $A$. salina larvaları üzerinde teratojenik etkide bulunduğunu, krom (III), krom (VI), bakır, klorobenzen, kloroform, dimetil sülfoksit (DMSO) ve fenol'ün ise teratojenik etkisinin olmadığını belirlemişlerdir. $\mathrm{Bu}$ çalışmanın sonuçları da yüksek konsantrasyondaki (1000 ppm) perkloroetilen'in A.salina larvaları üzerinde toksik etkisinin olduğunu göstermiştir. Perkloroetilen'in genotoksik etkilerine dair prokaryot ve ökaryotlarda gen mutasyonlarma, memeli hücrelerinde ise kromozom ve DNA hasarlarına neden olup olmadığını belirlemek üzere yapılan in vitro çalışma örnekleri vardır (ECETOC, 1990., IARC, 1995).

Yapılan bu çalışmaların sonuçları, perkloroetilen'in test edilen sistemlerde mutajenik olmadığını göstermiştir. Tespit edilen birkaç zayıf mutajenik aktivitenin test örneklerinde bulunan mutajenik stabilizatörlerden kaynaklanmış olabileceği belirtilmiştir (PSLAR,1993., IARC, 1995). Intraperitonal olarak tetrakloroetilen ile muamele edilen A-suşu farelerinde akciğer tümörlerinin sıklığında artış olmadığı (Theiss ve ark., 1977; Maronpot ve ark., 1986), ve tetrakloroetilen'in kanserojen olmadığı (Van Duuren ve ark. 1979) ve tetrakloroetilen'in karaciğer tümörünün oluşmasında tümör ilerletici olarak potansiyeli olduğuna dair veriler olmasına karşın, bu veriler yetersizdir (Milman ve ark., 1988; Lundberg ve ark., 1987). Hamile farelerin tetrakloroetilene maruz birakılmaları sonucunda, farelerin embriyonik ve fetal dokularında tetrakloroetilen kalıntıları olduğu bulunmuştur (Ghantous ve ark., 1986). Ancak bu çalışmalardan elde edilen sinırl verilere dayanarak, gebe farelerde doza bağlı olarak embriyo ve fetüste düşük oranda toksik etkiler göstermesine rağmen, bu çalışmadan elde edilen sinırlı veri nedeni ile tetrakloroetilenin teratojenik etkisinin olduğunu söylemek zordur. Bir dizi genetik son noktanın (end-points) incelenmesine dayanarak yapılan gerek in vitro ve gerekse in vivo çalışmalar tetrakloroetilen'in genotoksik olmadığını göstermiştir (PSLAR, 1993). Aranyi ve ark., (1986), 3 saat boyunca $50 \mathrm{ppm}\left(339 \mathrm{mg} / \mathrm{m}^{3}\right)$ tetrakloroetilen ile muamele edilen CD1 farelerinde, tetrakloroetilen'in streptococcal zatürreye karşı direnç gelişmesinde etkili olduğunu ve kontroller ile karşılaştırıldığında akciğerlerdeki bakterisidal aktivitenin azaldığını rapor etmişlerdir. $25 \mathrm{ppm} \quad\left(170 \quad \mathrm{mg} / \mathrm{m}^{3}\right)^{\prime} l i k$ tetrakloroetilen ile muamele edilen farelerde ise, kontrolle karşılaştırıldığında önemli bir farkın olmadığı da belirlemişlerdir. Yine in vitro olarak
PERC'e maruz birakılan Çin hamster yumurtalık hücrelerinde herhangi bir kardeş kromatid değişimine veya kromozom hasarına rastlanılmamıştır (Galloway ve ark., 1987).

PERC'in deri üzerindeki sitotoksik potansiyelinin insan epidermal keratinosid (NHEK) hücreleri kullanılarak araştırıldığı bir çalışmanın sonuçları, PERC'nin farkl konsantrasyonlarda (0.01-31.6 mM) NHEK hücreleri üzerinde sitotoksik etkisinin bulunduğunu göstermiştir (Zhu ve ark., 2005). Tetrakloroetilen'in $0,20,40,60$ ve $80 \mathrm{mg} / \mathrm{L}$ dozları ile 96 saat (akut) ve $0,1.5,3,6,12$ ve $25 \mathrm{mg} / \mathrm{L}$ dozları ile de 10 gün (sub-kronik) süreyle muamele edilen bir günlük Japanese Medaka (Oryzias latipes) embriyoları üzerindeki potansiyel toksik etkileri araştırılmıştır. Çalışmada, yumurta/embriyo canlılı̆ğ, kuluçka kapasitesi ve morfolojik ve gelişimsel anormallikler dikkate alınmıştır. Subkronik dozlarla muamele edilen yumurtalarda embriyolardaki sağ kalım doz artışına bağlı olarak önemli derecede azalmıştır. Oryzias latipes embriyolarında gözlenen en önemli olumsuz gelişimsel etkiler arasında; yolk-kese ödemi, dolaşım sisteminin anormal gelişimi, perikardiyal ödem, skolyoz kanama ve kalp morfolojisinde kusurlar gözlenmiştir. Çalışmanın sonuçları, TCE'nin uygulama dozuna bağlı olarak Oryzias latipes embriyolarında teratojenik etkisinin olduğunu ortaya göstermiştir (Spencer ve ark., 2002).

$\mathrm{Bu}$ etkilerin yanısıra, PERC'in subkronik ve kronik inhalasyonuna maruz kaldıktan sonra, hayvanların karaciğer ve böbreklerinde kanserojen olmayan belirtilerin ortaya çıktığı, insanlarda görülen kronik nonkarsinojenik etkilerin baş ağrısı, renk görme bozukluğu, görsel mekansal işlev bozuklukları, hafıza, konsantrasyon ve entelektüel fonksiyonlarda azalma gibi nörolojik etkiler olduğu rapor edilmiştir (ATSDR 1997., USEPA 2003., Lee, 2008;). Yine insanlarda PERC'e mesleki olarak maruz kalma sonucunda kadınlarda adet döngüsünde bozukluklar ve düşük yapma gibi üreme üzerindeki bazı olumsuz etkilerin olduğu da rapor edilmiş olsa da, çalışmaların kısıtlılıkları nedeniyle PERC'in toksik etkileri hakkında kesin bir yargıya varılamamıştır (ATSDR 1997).

\section{SONUÇ}

Bu çalışmanın sonuçları in vitro ortamda PERC'e 24 saat maruz birakılan A.salina larvaları üzerindeki sitotoksik etkinin sadece 1000 ppm'lik konsantrasyonda ortaya çıtığını, diğer konsantrasyon aralıklarında (10 ve 100 ppm) ise sitotoksik etkisinin bulunmadığını göstermiştir. Ancak bu sonucun PERC'in farkl organizma ve hücreler üzerinde denenmesi ile elde edilecek verilerle desteklenmesi gerekmektedir. 


\section{TEŞEKKÜR}

Bu çalışmayı FEF-12030 No.lu Proje ile destekleyen Adnan Menderes Üniversitesi, Bilimsel Araştırma Projeleri Birimi'ne ve bu çalışma süresince verdiği destek ve yardımlardan dolayı Araş. Görev. Dr. Özlem Sultan ASLANTÜRK'e teşekkür ederiz. Bu eser, "Perkloretilen (PERC)'in Sitotoksik ve in-vitro Genotoksik Etkisinin Farklı Test Sistemleri İle Araştırılması" adlı Yüksek Lisans Tezinin bir bölümünün sonuçlarını kapsamaktadır.

\section{KAYNAKLAR}

Anonim 2004. Tetrachloroethylene. https://pubchem.ncbi.nlm.nih.gov/compound/tetrac hloroethylene\#section=Top. Hazırlanma Tarihi. 16.09.2004. Erişim Tarihi, 05.04.2018.

Anonim 2008. Artemia Kültürü. MEGEP (Meslekî Eğitim ve Öğretim Sisteminin Güçlendirilmesi Projesi). T.C. Millî Eğitim Bakanlığı, Ankara.

Aranyi C, O'Shea WJ, Graham JA, Miller FJ. 1986. The Effects of Inhalation of Organic Chemical Air Contaminants on Murine Lung Host Defences. Fund. Appl. Toxicol. 6: 713-720.

ATSDR (Agency for Toxic Substances and Disease Registry), 1997. Toxicological Profile for Tetrachloroethylene. (Public Health Service Report, No. TP-92/18).

Blair A, Steward PA, Tolbert PE, Graunan D, Moran,FX, Vaught J, Ryner J.1990. Cancer and Other Causes of Death Among a Cohort of Dry Cleaners. British Journal of Industrial Medicine. 47:162-168.

Choudhary IM, Thomsen WJ. 2001. Bioassay Techniques For Drug Development, Harwood Academic Publishers, 8-10.

ECETOC Technical Report. Brussels, European Centre for Ecotoxicology and Toxicology of Chemicals. 1990. Tetrachloroethylene: Assessment of human carcinogenic hazard. No. 37.

Fişek AG, Piyal B. 1991. İşçi Sağlığı Kılavuzu. Türk Tabipleri Birliği Yayını, Ankara.

Hartmann A, Speit G. 1995. Genotoxic Effects of Chemicals in The Single Cell Gel (SCG) Test with Human Blood Cells in Relation to the Induction of Sisterchromatid Exchanges (SCE). Mutat. Res. 346:49-56.

Galloway SM, Armstrong MJ, Reuben C, Colman S, Brown B, Cannon C, Bloom AD, Nakamura F, Ahmed M, Duk S, et al. 1987. Chromosome Aberrations and Sister Chromatid Exchanges in Chinese Hamster Ovary Cells: Evaluations of 108 Chemicals. Environ Mol Mutagen. 10 (Suppl 10):135.

Ghantous, H, BRG. Danielsson, L. Dencker, J, Gorczak, O. Vesterberg. 1986. Trichloroacetic Acid Accumulates in The Murine Amniotic Fluid after Tri- $^{-}$and Tetrachloroethylene İnhalation. Acta
Pharmacol. Toxicol. 58: 105-114.

IARC Monographs on the Evaluation of Carcinogenic Risks to Humans. World health Organization, International Agency for Research on Cancer. 1995. Dry Cleaning, Some Chlorinated Solvents and Other Industrial Chemicals. 63.:159-221, France.

Insanu M, Anggadiredja J, Kayser O. 2012. Curcacycline A and B-New Pharmacological Insights to an Old Drug. Int J Appl Res Nat Prod., 5: 26-34.

Karakaya AE. 1996. İş Yerlerinde Maruz Kalınan Kimyasallar ve Endüstri Toksikoljisi. İş̧i Sağllğı ve İş Güvenliği Bülteni, sayı:35, Ankara.

Kerster, HW, Schaeffer, DJ. 1983. Brine Shrimp (Artemia salina) Nauplii as a Teratogen Test System. Ecotoxicology and Environmental Safety 7(3):342-9.

Kokkali V, Katramados I, Newman JD. 2011. Monitoring The Effect of Metal Ions on The Mobility of Artemia salina nauplii. Biosensors 1 (2): 36-45.

Lee JS. 2008. Tetrachloroethylene (PCE) CAS Registry Number: 127-18-4. Development Support Document Final, April 15, 2008, Accessible 2013 Revised Odor Value: September 14, 2015.

Lewan L, Andersson M, Morales-Gomez P. 1992. The Use of Artemia salina in Toxicity Testing. ATLA, 20:297-301.

Libralato G, Prato E, Migliore L, Cicero AM, Manfra L. 2016. A Review of Toxicity Testing Protocols and Endpoints with Artemia spp. Ecological Indicators, 69: 35-49.

Lundberg I, Hogberg, J, Kronevi, T, Holmberg, B. 1987. Three İndustrial Solvents İnvestigated for Tumor Promoting Activity in The Rat Liver. Cancer Lett. 36: 29-33.

Manfra L, Savorelli F, Pisapia M, Magaletti E, Cicero AM. 2012. Long-term Lethal Toxicity Test with The Crustacean Artemia franciscana. JoVE, 62: 21822185.

Maronpot RR., Shimkin MB, Witschi H.P, Smith LH, Cline JM. 1986. Strain A-Mouse Pulmonary Tumor Test Results for Chemicals Previously Tested in The National Cancer Institute Carcinogenicity Tests. JNCI 76: 1101-1112.

Mclaughlin JL, Rogers LL, Anderson JE. 1998. The Use of Biological Assays to Evaluate Botanicals. Drug Inf J., 32: 513-24.

Milman HA., Story DA, Riccio ES, Sivak A, Tu AS, Williams A.S, Tong C, Tyson CA. 1988. Rat Liver Foci and in vitro Assays to Detect İnitiating and Promoting Effects of Chlorinated Ethanes and Ethylenes. Annal. N.Y. Acad. Sci. 534: 521-530.

Muzzullo MS, Grilli G, Lattanzi G, Prodi G, Turina MP, Colacci A. 1987. Evidence of DNA Binding Activity of Perchloroethylene. Res Commun Chem Pathol Pharmacol, 58(2): 215-235.

Nguta, JM., Mbaria, JM., Gakuya, DW., Gathumbi, PK., Kabasa, JD., Kiama, SG. 2011.Biological 
Screening of Kenya Medicinal Plants using Artemia salina L. (Artemiidae). Pharmacologyonline 2: 458478.

Nunes BS, Carvalho FD, Guilhermino LM, Van Stappen G. 2006. Use of The Genus Artemia in Ecotoxicity Testing. Environ Pollut., 144: 453-62.

Oran, Ö. 2016. Kuru Temizleme Atölyelerinde Çalışanların Maruz Kaldığı Kimyasal Risk Faktörlerinin İncelenmesi. Çalışma ve Sosya Güvenlik bakanlığı, İş Sağlığı ve Güvenliği Genel Müdürlüğü, İş Sağllğı ve Güvenliği Uzmanlık Tezi, $110 \mathrm{~s}$.

PSLAR, Priority Substances List Assessment Report Tetrachloroethylene. $1993 . \quad$ Canadian Environmental Protection Act. ISBN 0-662-21066-2 Cat. No. En-40-215/28E.

Potter CL, Chang LW, De Angelo AB, Daniel FB. 1996. Effects of Four Trihalomethanes on DNA Strand Breaks, Renal Hyaline Droplet Formation and Serum Testosterone in Male F-344 Rats. Cancer Lett., 106 (2) : 235-242.

Rajabi S, Ramazani A, Hamidi M, Tahereh N. 2015. Artemia salina as A Model Organism in Toxicity Assessment of Nanoparticles. Journal of Pharmaceutical Sciences, 23: 20. DOI 10.1186/s40199-015-0105-x.

Solis PN, Wright CW, Anderson MM, Gupta MP, Phillipson JD 1993. Amicrowell Cytotoxicity Assay using Artemia salina. Plant Med., 59: 250-252.

Spencer HB, Hussein WR, Tchounwou PB. 2002. Effects of Tetrachloroethylene on The Viability and Development Of Embryos of The Japanese Medaka, Oryzias latipes. Arch. Environ. Contam. Toxicol., 42: 463-469. DOI: 10.1007/s00244-001-0050-1.

Theiss JC, Stoner GD, Shimkin MB, Weisberger EK. 1977. Test for Carcinogenicity of Organic Contaminants of United States Drinking Waters by
Pulmonary Tumor Response in Strain A Mice. Cancer. Res. 37: 2717-2720.

United States Environmental Protection Agency (USEPA).2003. Neurotoxicity of Tetrachloroethylene (Perchloroethylene): Discussion Paper, EPA/600/P-03/005A. Washington, D.C. Available from: http://cfpub.epa.gov/ncea/cfm/ recordisplay.cfm?deid $=75193$.

Ünsal Ü. 2013. Perkloretilen (PERC)'in Sitotoksik ve in vitro Genotoksik Etkisinin Farkl Test Sistemleri İle Araştırılması. Adnan Menderes Üniversitesi, Fen Bilimleri Enstitüsü, Biyoloji Anabilim Dalı, Yüksek Lisans Tezi,130 s.

Van Duuren BL, Goldschmidt BM, Loewengar G, Smith AC, Melchionne S, Seldman I, Roth D. 1979. Carcinogenicity of Halogenated Olefinic and Aliphatic Hydrocarbons in Mice. JNCI 63: 14331439.

Walles SA. 1986. Induction of Single-Strand Breaks in DNA of Mice by Trichloroethylene and Tetrachloroethylene. Toxicol Lett., 31:31-35.

Wang JL, Chen WL, Tsai SY, Sung PY, Huang RN. 2001. An in vitro Model for Evaluation of Vaporous Toxicity of Trichloroethylene and Tetrachloroethylene to CHO-K1 Cells. Chem Biol Interact., 137(2):139-154.

White IN, Razvi N, Gibbs AH, Davies AM, Manno M, Zaccaro C, De Matteis F, Pähler A, Dekant W. 2001. Neoantigen Formation and Clastogenic Action of HCFC-123 and Perchloroethylene in Human MCL5 cells. Toxicol Lett., 124:129-138.

Zhu Qi-Xing, Shen T, Ding R, Liang Zhao-Zhao, Zhang, Xue-Jun. 2005. Cytotoxicity of Trichloroethylene and Perchloroethylene on Normal Human Epidermal Keratinocytes and Protective Role of Vitamin E. Toxicology, 209: 55-67. 